\title{
The Association of Metabolic Syndrome and Vitamin D in Korean Menopausal Women: Korea National Health and Nutrition Survey, 2010 2012
}

Eun Kyung Roh ${ }^{1}$ and Hyun Yoon ${ }^{2}$

\section{한국 폐경기 여성에서 대사증후군과 비타민 D의 관련성: 2010 2012 국민건강영양조사에 근거하여}

\author{
노은경 ${ }^{1}$, 윤 현 $^{2}$ \\ ${ }^{1}$ 동강대학교 보건행정학과, ${ }^{2}$ 한려대학교 임상병리학과
}

\begin{abstract}
The aim of this study was to assess the association of metabolic syndrome and Vitamin D in Korean adults. The study subjects were Korean menopausal woman $(n=4,340)$ who participated in the Korea National Health and Nutrition Examination Survey 2010 2012. After adjusting for factors such as age, body mass index, total cholesterol, smoking, and regular exercise, the mean 25(OH)D levels (M \pm SE) decreased with increasing metabolic syndrome score (MSS) (MSS 0, 18.18 \pm 0.29 $\mathrm{ng} / \mathrm{Ml}$; MSS 1, $18.09 \pm 0.21 \mathrm{ng} / \mathrm{mL}$; MSS 2, $18.07 \pm 0.19 \mathrm{ng} / \mathrm{mL} ; \mathrm{MSS} 3,18.04 \pm 0.21 \mathrm{ng} / \mathrm{mL}$; MSS $\geq 4,17.27 \pm 0.23 \mathrm{ng} / \mathrm{mL})$, and the mean $25(\mathrm{OH}) \mathrm{D}$ level $(\mathrm{M} \pm \mathrm{SE})$ for metabolic syndrome $(17.66 \pm 0.16 \mathrm{ng} / \mathrm{mL})$ decreased in comparison to non-metabolic syndrome $(18.11 \pm 0.14 \mathrm{ng} / \mathrm{mL})$. In conclusion, our results suggest that an increase in metabolic syndrome score or metabolic syndrome are inversely associated with the vitamin D levels.
\end{abstract}

Keywords: Metabolic syndrome, Metabolic syndrome score, Vitamin D, Postmenopausal women

This is an Open Access article distributed under the terms of the Creative Commons Attribution Non-Commercial License (http://creativecommons.org/licenses/by-nc/4.0) which permits unrestricted non-commercial use, distribution, and reproduction in any medium, provided the original work is properly cited.

Copyright ( 2015 The Korean Society for Clinical Laboratory Science. All rights reserved.
Corresponding author: Hyun Yoon

Department of Biomedical Laboratory Science, Hanlyo University, Gwangyang 57764, Korea Tel: 82-61-760-1150

E-mail: yh9074@yahoo.co.kr

Received: October 27, 2015 Revised $1^{\text {st. }}$ November 5, 2015

Revised 2 ${ }^{\text {nd }}$ : November 6, 2015 Revised $3^{\text {rd }}$ : November 6, 2015 Accepted: November 6, 2015

\section{서 론}

대사증후군은 복부비만과 고혈압, 지질대사이상 및 공복혈당장 애를 포함한 대사이상을 동반하는 질환으로 예전에는 Syndrome $\mathrm{X}$ 라고 불렸으며, 인슐린에 대한 저항성을 나타낸다(Reaven 등, 1998). 대사증후군의 발생은 심혈관계 질환과 뇌혈관질환 및 제 2 형 당뇨병의 발생률을 증가시키고, 총 사망률과 관련이 높다고 알 려져 있다(Isomaa 등, 2001; McNeill 등, 2005). 미국에서 폐경기 여성의 대사증후군 유병률은 약 $40 \%$ 이며(Ford 등, 2002), 우리나
라에서는 약 $54 \%$ 의 대사증후군 유병률은 보이고 있다(Shin, 2014). 폐경기 여성은 폐경 전 여성에 비하여 고밀도 콜레스테롤이 감소하지만 중성지방, 총 콜레스테롤 및 저밀도 콜레스테롤은 증가 하는 것으로 알려져 있다(Carr, 2003; Kim 등, 2007). 폐경기 여성 은 이와 같은 지질이상으로 인하여 혈 중 glucose 및 인슐린 증가와 같은 대사 및 내분비적 변화가 동반되고(Lee 등, 2005), 심혈관 및 뇌혈관 질환과 대사증후군 발생률도 폐경 이전보다 현저한 증가를 보인다(Moon 등, 2003; Kim 등, 2007).

비타민 D는 호르몬 전구체로서 vitamin D2는 버섯 등의 일부 식 
물과 고등어와 같은 기름진 생선 등에도 존재하지만 대부분 자외선 으로 합성된다. 비타민 $\mathrm{D}$ 의 혈중 농도는 비 활성형인 25-hydroxyvitamin D [25(OH)D]를 측정하여 체내 총 비타민 D 상태를 추정 하는데, 그 이유는 활성형인 1,25-dihydroxyvitamin D보다 반감 기가 2 3주로 길기 때문이다(Hollis와 Horst, 2007; Prentice 등, 2008). 비타민 D의 기능은 골다공증과 당뇨의 발병을 억제하고 (Shin과 Om, 2009), 면역계의 정상기능 유지와 유방암, 전립선암 을 예방하고 류마티즘에 효과가 있다고 알려져 있고(Misr 등, 2008), 비타민의 결핍은 연골 무기질화 장애와 연골 성장판의 비정 상적인 기질화(organization)로 발생하는 구루병과 인지기능 장 애, 우울증의 중요한 기여 요인이 된다(Kim, 2007).

최근, 비타민 $\mathrm{D}$ 과 관련된 연구는 대사증후군의 구성요인인 동시 에 혈관질환의 위험요인에 해당하는 고혈압, 비만, 고지혈증, 당뇨 등과의 관련성에 대한 연구가 많이 진행되고 있지만(Brandenburg 등, 2012; Cozzolino 등, 2012; Muscogiuri 등, 2012; Park과 Lee, 2012), 대사증후군의 위험인자인 고밀도 콜레스테롤이 감소하고 중성지방, 총 콜레스테롤 및 저밀도 콜레스테롤이 증가하는 것으로 알려져 있는 폐경기 여성을 대상으로 실시한 연구는 드물다. 따라 서 본 연구는 대한민국도 심혈관계 질환과 대사증후군이 증가하고 있고, 대한민국 성인의 비타민 D 결핍이 특히 심하다고 알려져 있 는 상황에서 제 5 기 국민건강영양조사 자료를 이용하여 한국 폐경 기 여성을 대상으로 혈중 비타민 D와 대사증후군의 관련성에 대하 여 알아보고자 하였다.

\section{재료 및 방법}

\section{1. 연구대상}

본 연구는 제 5기 국민건강영양조사의 자료(2010 2012년)를 이용하였다. 조사참여자수는 25,499 명이었고, 이 중 폐경기 여성 은 5,108 명이었다. 5,108 명 중 건강 설문에서 불충분한 응답과 혈 압 및 혈액검사 및 비타민 $\mathrm{D}$ 등의 검사결과가 누락이 되어있는 대상 자 768 명을 제외한 총 4,340 명을 최종 분석 대상자로 하였다. 제 5 기 국민건강영양조사 자료는 질병관리본부 연구윤리심의위원회 의 심의 및 승인을 받았다(승인번호; 2010-02CON-21-C, 201102CON-06-C, 2012-01EXP-01-2C).

\section{2. 자료수집}

본 연구는 2010년도부터 2012년도 까지 3년 동안 시행된 제 5 기 국민건강영양조사 자료를 이용하였다. 조사항목으로는 대상자 들의 연령, 허리둘레(waist measurement, WM), 체질량지수 (body mass index, BMI), 안정 시 혈압, 아침공복시의 혈액검사 등
이었다.

\section{3. 대상자의 특성}

1) 일반적 특성 및 혈액화학검사

대상자 중 연령은 50세 미만군, 50 59세군, 60 69세군, 70세 이상 군으로 구분하였다. 신체계측은 체질량지수, 허리둘레, 최종 수축기혈압(systolic blood pressure, SBP), 최종 이완기혈압 (diastolic blood pressure, DBP)의 측정값을 사용하였고, 혈액화 학검사는 총 콜레스테롤(Total cholesterol, TC), 중성지방(Triglyceride, TG), 저밀도 콜레스테롤(HDL-cholesterol, HDL-C), 공 복시 혈당(Fasting blood glucose, $\mathrm{FBG}$ ) 및 25(OH)D 등의 측정값 을 사용하였다.

\section{2) 대사증후군 및 비타민 $D$}

대사증후군의 진단 기준은 Revised NCEP-ATP III의 기준 (Revised NCEP-ATP III, 2001)에 의하여 높은 중성지방혈증은 $\mathrm{TG} \geq 150 \mathrm{mg} / \mathrm{dL}$ 으로 정의하였고, 낮은 고밀도 콜레스테롤혈증은 $\mathrm{HDL}-\mathrm{C}<50 \mathrm{mg} / \mathrm{dL}$ 미만으로 정의하였다. 높은 혈당은 $\mathrm{FBG} \geq$ $100 \mathrm{mg} / \mathrm{dL}$ 으로 정의하였고, 높은 혈압은 SBP $\geq 130 \mathrm{mmHg}$ 이거 나, $\mathrm{DBP} \geq 85 \mathrm{mmHg}$ 일 때로 정의하였다. 복부비만은 허리둘레를 $\mathrm{APC}$ (Asia-pacific criteria)의 기준에 따라 $\mathrm{WM} \geq 80 \mathrm{~cm}$ 으로 정 의하였다(WHO, 2000). 이들 5개 항목 중 정상치보다 높거나 낮은 항목이 3개 이상 존재할 때를 대사증후군으로 분류하였다. metabolic syndrome score (MSS)는 대사증후군의 5가지 위험요인인 높은 혈압, 높은 혈당, 복부비만, 높은 중성지방혈증, 낮은 고밀도 콜레스테롤혈증 등을 Score로 분류한 것으로 대사증후군의 5 가지 중 위험요인을 가지고 있지 않는 경우를 MSS 0, 위험요인 중 1 개를 가지고 있는 경우를 MSS 1, 위험요인 중 2개를 가지고 있는 경우를 MSS 2, 위험요인 중 3개를 가지고 있는 경우를 MSS 3, 위험요인 중 4 개 이상 가지고 있는 경우를 MSS $\geq 4$ 로 분류하였다(Yoon 등, 2015).

\section{4. 자료처리 및 분석}

자료의 통계처리는 SPSS WIN version 18.0 (SPSS Inc., Chicago, IL, USA) 통계프로그램을 이용하였다. 대상자의 특성에 대한 분포는 빈도와 백분율로 나타내었고 연속형 자료는 평균과 표 준편차로 표시하였다. 대상자의 특성에 따른 $25(\mathrm{OH}) \mathrm{D}$ 는 independent t-test와 ANOVA test를 이용하여 분석하였다. $25(\mathrm{OH}) \mathrm{D}$ 에 대한 공분산분석을 시행하여 $25(\mathrm{OH}) \mathrm{D}$ 에 영향을 주는 다른 요 인을 보정한 후 대사증후군과 $\mathrm{MSS}$ 에 따른 $25(\mathrm{OH}) \mathrm{D}$ 의 평균값을 비교하였다. 모든 통계량의 유의수준은 $p<0.05$ 로 판정하였다. 


\section{결 과}

\section{1. 연구대상자의 일반적 특성}

연구대상자의 일반적 특성은 Table 1과 같다. 대상자들의 평균

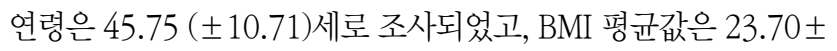
$3.20 \mathrm{~kg} / \mathrm{m}^{2}$ 이었다. 대상자들의 혈액검사 중 TC, TG, HDL-C 평균 값은 각각 $191.10 \pm 38.34 \mathrm{mg} / \mathrm{dL}, 128.14 \pm 97.08 \mathrm{mg} / \mathrm{dL}$, $51.46 \pm 12.14 \mathrm{mg} / \mathrm{dL}$ 이었고, $\mathrm{FBG}$ 평균값은 95.68 17.09 $\mathrm{mg} / \mathrm{dL}$ 이었다. 대상자들의 혈압에 대한 수치 중 $\mathrm{SBP}$ 와 DBP 평균 값은 각각 $123.32 \pm 12.37 \mathrm{mmHg}, 75.50 \pm 9.56 \mathrm{mmHg}$ 이었다. 대 상자들 중 비타민 $\mathrm{D}$ 결핍 $(25(\mathrm{OH}) \mathrm{D}<15)$ 에 해당하는 대상자는

Table 1. General characteristics of research subjects

\begin{tabular}{|c|c|c|}
\hline Variables & N (\%) & $M \pm S D$ \\
\hline Age (year) & & $63.55 \pm 9.32$ \\
\hline$<50$ & $167(3.8)$ & \\
\hline $50 \sim 59$ & $1,473(34.0)$ & \\
\hline $60 \sim 69$ & $1,428(32.9)$ & \\
\hline$\geq 70$ & $1,272(29.3)$ & \\
\hline \multicolumn{3}{|l|}{ Smoking } \\
\hline Non-smoker & 4,031 (92.9) & \\
\hline Ex-smoker & $138(3.2)$ & \\
\hline Current smoker & 171 (3.9) & \\
\hline \multicolumn{3}{|l|}{ Alcohol drinking } \\
\hline Non-drinker & $2,229(54.4)$ & \\
\hline Drinker & $2,111(48.6)$ & \\
\hline \multicolumn{3}{|l|}{ Regular exercise } \\
\hline No & $3,940(90.8)$ & \\
\hline Yes & $398(9.2)$ & \\
\hline Metabolic syndrome score (MSS) & & $2.12 \pm 1.29$ \\
\hline 0 & $539(12.4)$ & \\
\hline 1 & 947 (21.8) & \\
\hline 2 & $1,106(25.5)$ & \\
\hline 3 & $941(21.7)$ & \\
\hline$\geq 4$ & $807(18.6)$ & \\
\hline \multicolumn{3}{|l|}{ Metabolic syndrome } \\
\hline MSS $<3$ & $2,592(59.7)$ & \\
\hline MSS $\geq 3$ & $1,748(40.3)$ & \\
\hline $25(\mathrm{OH}) \mathrm{D}(\mathrm{ng} / \mathrm{mL})$ & & $17.94 \pm 6.29$ \\
\hline$<15$ & $1,535(35.4)$ & \\
\hline$\geq 15$ & $2,805(64.6)$ & \\
\hline BMI $\left(\mathrm{kg} / \mathrm{m}^{2}\right)$ & & $24.29 \pm 3.28$ \\
\hline WM (cm) & & $82.21 \pm 9.22$ \\
\hline TC (mg/dL) & & $201.61 \pm 37.73$ \\
\hline TG (mg/dL) & & $135.73 \pm 84.84$ \\
\hline $\mathrm{HDL}-\mathrm{C}(\mathrm{mg} / \mathrm{dl})$ & & $52.53 \pm 12.38$ \\
\hline FBG (mg/dL) & & $100.64 \pm 22.83$ \\
\hline SBP (mmHg) & & $127.22 \pm 17.89$ \\
\hline DBP (mmHg) & & $76.47 \pm 9.94$ \\
\hline
\end{tabular}

Abbreviation: 25(OH)D, 25-hydroxyvitamin D; BMI, body mass index; WM, waist measurement; TC, total cholesterol; TG, triglyceride; HDL-C, HDL-cholesterol; FBG, fasting blood glucose, $\mathrm{SBP}$, systolic blood pressure; DBP, diastolic blood pressure.
$1,535$ 명(35.4\%)이었고, 대사증후군(MSS $\geq 3)$ 에 해당하는 대상자 는 1,748 명(40.3\%)이었다.

\section{2. 대상자의 특성에 따른 $25(\mathrm{OH}) \mathrm{D}$ 의 평균값 비교}

대상자의 특성에 따른 $25(\mathrm{OH}) \mathrm{D}$ 의 평균값은 Table 2 와 같다. 대 상자의 특성 중 $25(\mathrm{OH}) \mathrm{D}$ 에서 평균차이를 보이는 변수는 연령 ( $p=0.001)$, 흡연습관 $(p=0.045)$, 중등도 신체활동 $(p=0.035), \mathrm{BMI}$ $(p<0.001)$ 등이었다. 대사증후군 구성요소 중에서는 복부비만

Table 2. Serum 25(OH)D levels by subject characteristics

$\mathrm{M} \pm \mathrm{SD},(\mathrm{N}=4,340)$

\begin{tabular}{|c|c|c|}
\hline Variables & $25(\mathrm{OH}) \mathrm{D}(\mathrm{ng} / \mathrm{mL})$ & $p$-value \\
\hline Age (years) & & 0.001 \\
\hline$<50$ & $16.76 \pm 5.37$ & \\
\hline $50 \sim 59$ & $17.56 \pm 5.83$ & \\
\hline $60 \sim 69$ & $18.20 \pm 6.43$ & \\
\hline$\geq 70$ & $18.23 \pm 6.70$ & \\
\hline Smoking & & 0.045 \\
\hline Non-smoker & $18.00 \pm 6.34$ & \\
\hline Ex-smoker & $17.18 \pm 5.52$ & \\
\hline Current smoker & $17.00 \pm 5.65$ & \\
\hline Alcohol drinking & & 0.357 \\
\hline Non-drinker & $17.85 \pm 6.41$ & \\
\hline Drinker & $18.03 \pm 6.16$ & \\
\hline Regular exercise & & 0.035 \\
\hline No & $17.87 \pm 6.28$ & \\
\hline Yes & $18.59 \pm 6.39$ & \\
\hline Body mass index $\left(\mathrm{kg} / \mathrm{m}^{2}\right)$ & & $<0.001$ \\
\hline$<25$ & $18.19 \pm 6.47$ & \\
\hline$\geq 25$ & $17.52 \pm 5.96$ & \\
\hline Total cholesterol (mg/dL) & & 0.099 \\
\hline$<200$ & $18.10 \pm 6.51$ & \\
\hline$\geq 200$ & $17.78 \pm 6.06$ & \\
\hline Waist measurement $(\mathrm{cm})$ & & 0.042 \\
\hline Normal* & $18.17 \pm 6.47$ & \\
\hline Abdominal obesity $^{\dagger}$ & $17.77 \pm 6.16$ & \\
\hline Triglycerides (mg/dL) & & 0.003 \\
\hline Normal $^{\ddagger}$ & $18.13 \pm 6.30$ & \\
\hline Elevated triglycerides ${ }^{\S}$ & $17.52 \pm 6.26$ & \\
\hline HDL-cholesterol (mg/dL) & & 0.036 \\
\hline Normal" & $18.11 \pm 6.32$ & \\
\hline Reduced HDL-C $C^{\pi}$ & $17.71 \pm 6.24$ & \\
\hline Fasting blood glucose (mg/dL) & & 0.892 \\
\hline Normal ${ }^{\star *}$ & $17.93 \pm 6.17$ & \\
\hline Elevated $\mathrm{FBG}^{\dagger+}$ & $17.95 \pm 6.50$ & \\
\hline Blood pressure $(\mathrm{mm} / \mathrm{Hg})$ & & 0.029 \\
\hline Normal $^{\ddagger \ddagger}$ & $18.13 \pm 6.23$ & \\
\hline Elevated blood pressure ${ }^{\S}$ & $17.71 \pm 6.35$ & \\
\hline
\end{tabular}

*Normal is defined as WM $<80 \mathrm{~cm}$; ${ }^{\dagger}$ Abdominal obesity is defined as WM $\geq 80 \mathrm{~cm} ;{ }^{\dagger}$ Normal is defined as TG $<150 \mathrm{mg} / \mathrm{Dl}$; ${ }^{\S}$ Elevated triglyceride is defined as TG $\geq 150 \mathrm{mg} / \mathrm{dL}$; "Normal is defined as $\mathrm{HDL}-\mathrm{C} \geq 50 \mathrm{mg} / \mathrm{dL}$; "Reduced $\mathrm{HDL}-\mathrm{C}$ is defined as $\mathrm{HDL}-\mathrm{C}<50 \mathrm{mg} / \mathrm{dL}$; ${ }^{*}$ Normal is defined as FBG $<100 \mathrm{mg} / \mathrm{dL}$; ${ }^{+\dagger}$ Elevated FBG is defined as FBG $\geq 100 \mathrm{mg} / \mathrm{dL}$; ${ }^{\ddagger \neq}$ Normal is defined as SBP $<130 \mathrm{mmHg}$ or DBP $<85 \mathrm{mmHg}{ }^{\&}{ }^{\S}$ Elevated blood pressure is defined as SBP $\geq 130 \mathrm{mmHg}$ or DBP $\geq 85 \mathrm{mmHg}$. 
Table 3. Comparisons of serum 25(OH)D levels for metabolic syndrome and MSS

\begin{tabular}{ccccc}
\hline Variables & $\begin{array}{c}25(\mathrm{OH}) \mathrm{D} \\
(\mathrm{ng} / \mathrm{mL}) \\
\text { Non-adjusted } \\
(\mathrm{M} \pm \mathrm{SD})\end{array}$ & $p$-value & $\begin{array}{c}25(\mathrm{OH}) \mathrm{D} \\
(\mathrm{ng} / \mathrm{mL}) \\
\text { Adjusted } \\
(\mathrm{M} \pm \mathrm{SE})\end{array}$ & $p$-value \\
\hline MSS & & 0.004 & & 0.041 \\
0 & $18.24 \pm 6.40$ & & $18.18 \pm 0.29$ & \\
1 & $18.16 \pm 6.24$ & & $18.09 \pm 0.21$ & \\
2 & $18.09 \pm 6.33$ & & $18.07 \pm 0.19$ & \\
3 & $18.02 \pm 6.06$ & & $18.04 \pm 0.21$ & \\
$\geq 4$ & $17.17 \pm 6.44$ & & $17.27 \pm 0.23$ & \\
Non-MetS & $18.15 \pm 6.31$ & 0.007 & $18.11 \pm 0.14$ & 0.042 \\
MetS & $17.62 \pm 6.25$ & & $17.66 \pm 0.16$ & \\
\hline
\end{tabular}

Abbreviation: MSS, metabolic syndrome score; MetS, metabolic syndrome.

*Adjusted for age, BMI, TC, smoking, and regular exercise.

( $p=0.042)$, 높은 중성지방 $(p=0.003)$, 낮은 HDL-C ( $p=0.036)$, 높 은 혈압 $(p=0.029)$ 등이었고, 높은 혈당 $(p=0.892)$ 은 $25(\mathrm{OH}) \mathrm{D}$ 의 평균값에서 유의한 차이가 없었다.

\section{3. 대사증후군과 $\mathrm{MSS}$ 에 따른 $25(\mathrm{OH}) \mathrm{D}$ 의 평균비교}

대사증후군과 MSS에 따른 $25(\mathrm{OH}) \mathrm{D}$ 의 평균비교는 Table 3과 같다. 연령, $\mathrm{BMI}, \mathrm{TC}$, 흡연습관, 중등도 신체활동 등을 보정한 후 $\mathrm{MSS}$ 에 따른 $25(\mathrm{OH}) \mathrm{D}$ 의 평균값 $(\mathrm{M} \pm \mathrm{SE})$ 은 $\mathrm{MSS} 0$ 이 $18.18 \pm 0.29$ $\mathrm{ng} / \mathrm{dL}$ 이었고, MSS 1이 $18.09 \pm 0.21 \mathrm{ng} / \mathrm{dL}$, MSS 2가 $18.07 \pm$ $0.19 \mathrm{ng} / \mathrm{dL}, \mathrm{MSS} 3$ 이 $18.04 \pm 0.21 \mathrm{ng} / \mathrm{dL}, \mathrm{MSS} 4$ 가 $17.27 \pm 0.23$ $\mathrm{ng} / \mathrm{dL}$ 로 MSS가 증가할수록 $25(\mathrm{OH}) \mathrm{D}$ 의 평균값이 감소하였고 ( $p=0.041$ ), 연령, BMI, TC, 흡연습관, 중등도 신체활동 등을 보정 한 후, 대사증후군에 따른 $25(\mathrm{OH}) \mathrm{D}$ 의 평균값 $(\mathrm{M} \pm \mathrm{SE})$ 에서도 비 대

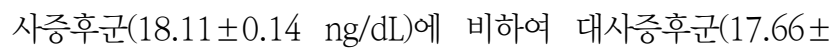
$0.16 \mathrm{ng} / \mathrm{dL})$ 의 $25(\mathrm{OH}) \mathrm{D}$ 의 평균값 $(\mathrm{M} \pm \mathrm{SE})$ 이 유의하게 감소하였 다 $(p=0.042)$.

\section{고 찰}

본 연구는 국민건강영양조사 자료(2010 2012)를 이용하여 폐 경기 여성에서 대사증후군과 비타민 $\mathrm{D}$ 의 관련성에 대한 연구이다. 본 연구의 주요결과는 비타민 D에 대한 관련변수를 보정한 후에도 비 대사증후군에 비하여 대사증후군의 $25(\mathrm{OH}) \mathrm{D}$ 의 평균값 $(\mathrm{M} \pm \mathrm{SE})$ 이 유의하게 낮았고, 대사증후군 구성요소의 증가에 따라 $25(\mathrm{OH}) \mathrm{D}$ 의 평균값 $(\mathrm{M} \pm \mathrm{SE})$ 이 유의하게 감소하였다는 결과이다(Table 3).

비타민 $\mathrm{D}$ 는 심·뇌혈관질환과 고혈압, 당뇨 및 골다공증을 예방 한다고 알려져 있는데(Shin 과 Om, 2009), 비타민 D의 결핍은 당 뇨와 고혈압의 발생률을 증가시키고 동맥경화증과 심혈관의 석회
화를 가속화 시킨다(Hollis 등, 2007). 또한 각각의 대사증후군 구 성요소는 관상동맥의 위험요소이며, 이들이 군집적으로 나타나는 대사증후군은 심혈관계 질환과 뇌혈관질환 및 제 2 형 당뇨병의 발 생률을 증가시킨다(Meigs, 2000; Grundy, 2007).

비타민 D와 대사증후군에 대한 연구에서, Lu 등(2009)은 50 70세의 베이징과 상하이 노인을 대상으로 실시한 연구에서 비타민 $\mathrm{D}$ 정상군(24.4\%)에 비하여 비타민 D 결핍군(69.2\%)의 대사증후 군 발생률(p-trend=0.0002)이 높았다. 또한 Park 등(2012)은 60 세 이상의 한국 노인을 대상으로 실시한 연구에서 $25(\mathrm{OH}) \mathrm{D}$ 는 $\mathrm{TG}$ $(p=0.023), \mathrm{SBP}(p=0.002), \mathrm{DBP}(p<0.001)$ 의 증가와 관련이 있 었고, 대사증후군의 발생률[Odds Ratio (OR): $1.73,95 \%$ Confidence interval (CI): 1.13-2.66]의 증가와 관련이 있었다. 반대 로, Kahder 등(2011)은 18세 이상의 요르단 성인을 대상으로 실시 한 연구에서 25(OH)D는 대사증후군 및 대사증후군 구성요소 모두 와 연관성이 없었다. 이와 같이 비타민 D와 대사증후군에 대한 연 구결과는 나라와 인종, 연령층과 질병의 유무에 따라 다르게 나타 나기 때문이다. 본 연구결과에서 대사증후군 구성요소 중 높은 혈 압은 $25(\mathrm{OH}) \mathrm{D}$ 와 관련이 없었지만, 대사증후군의 구성요소가 증 가함에 따라 $25(\mathrm{OH}) \mathrm{D}$ 가 감소하였고 $(p=0.041)$, 비 대사증후군에 비하여 대사증후군의 $25(\mathrm{OH}) \mathrm{D}$ 가 감소하였다 $(p=0.042)$.

대사증후군에서 비타민 $\mathrm{D}$ 가 감소하는 이유는 첫째, 본 연구는 대한민국의 대표적 지표인 제 5기 국민건강영양조사자료(2010 2012)를 이용한 연구로 대상자는 폐경기 여성이다. 여성은 폐경으 로 인하여 에스트로겐분비의 감소로 체지방 분포에서 변화가 나타 난다. 이로 인하여 내장지방의 증가에 의한 복부비만의 증가로 대 사증후군의 발생 위험도가 증가한다(Lee 등, 2005). 비만과 복부비 만은 대사증후군의 강력한 위험인자이며, 비타민 $\mathrm{D}$ 의 감소와 관계 가 있다. Lee 등(2013)은 한국 청소년 1,660명을 대상으로 실시한 serum $25(\mathrm{OH}) \mathrm{D}$ 와 비만 및 대사증후군에 대한 연구에서 비만 청소 년에서 비타민 $\mathrm{D}$ 가 유의하게 감소한다고 하였고 $(p<0.001)$, Lagunova 등(2011)은 비만에서 비타민 D가 감소하는 이유를 비 만인 사람은 비타민 D가 신장에서 $1,25(\mathrm{OH}) \mathrm{D} 2$ 로 전환되는 과정 에서 문제가 있을 것으로 추측하고 있다. 둘째, 비타민 $\mathrm{D}$ 는 부갑상 선 호르몬(parathyroid hormone, PTH)과 역 상관관계가 있다. Guasch 등(2012)은 스페인여성 316명을 대상으로 실시한 연구에 서 $\mathrm{BMI}$ 가 증가할수록 PTH가 증가하였고 $(p<0.001)$, BMI의 증가 가 부갑상선호르몬의 증가와 비타민 $\mathrm{D}$ 의 감소에 영향을 주는 가장 주요인자라고 하였다. 또한, Lee 등(2015)은 2011년 국민건강영 양조사자료를 이용한 복부비만과 PTH에 대한 연구에서 정상군에 비하여 복부 비만군에서 고 $\mathrm{PTH}$ 군(PTH $>65 \mathrm{ng} / \mathrm{L})$ 의 OR값(OR: 1.19 , CI: $1.02-1.39)$ 이 유의하게 증가하였다. 본 연구의 결과에서 
대사증후군 및 대사증후군의 구성요소의 증가가 $25(\mathrm{OH}) \mathrm{D}$ 수준을 감소시키는지, 25(OH)D 수준이 대사증후군 및 대사증후군의 구 성요소를 증가시키는지는 알 수 없다. 그러나 비 대사증후군에 비 하여 대사증후군의 $25(\mathrm{OH}) \mathrm{D}$ 수준이 낮은 이유로 대사증후군 구성 요소가 증가할수록 25(OH)D 수준이감소하기 때문이라고 사료된다. 그러나 본 연구는 제한점이 있다. 국민건강영양조사를 이용한 단면연구이기 때문에 비타민 D와 대사증후군의 인과관계를 설명 할 수가 없고, 향후 추적조사를 통해서 비타민 D와 대사증후군에 대한 코호트 연구를 시행할 수 있다면 이들의 인과관계를 확인하기 위한 더욱더 정확한 결과를 얻을 수 있을 것으로 기대된다.

\section{요 약}

본 연구는 국가자료인 제 5기 국민건강영양조사 자료(2010 2012)를 이용하여 폐경기 여성 $(n=4,340)$ 에서 대사증후군과 비타 민 $\mathrm{D}$ 의 관련성을 평가하고자 실시하였다. 연구결과에서 연령, $\mathrm{BMI}, \mathrm{TC}$, 흡연습관 및 중등도 신체활동을 보정한 후, 25(OH)D에 대한 평균값 $(\mathrm{M} \pm \mathrm{SE})$ 이 MSS 0은 $18.18 \pm 0.29 \mathrm{ng} / \mathrm{mL}, \mathrm{MSS} 1$ 은 $18.09 \pm 0.21 \mathrm{ng} / \mathrm{mL}, \mathrm{MSS} 2$ 는 $18.07 \pm 0.19 \mathrm{ng} / \mathrm{mL}, \mathrm{MSS} 3$ 은 $18.04 \pm 0.21 \mathrm{ng} / \mathrm{mL}, \mathrm{MSS} \geq 4$ 는 $17.27 \pm 0.23 \mathrm{ng} / \mathrm{mL}$ 로 MSS가 증가할수록 감소하였고( $p=0.041)$, 비 대사증후군(18.11 \pm 0.14 $\mathrm{ng} / \mathrm{mL})$ 에 비하여 대사증후군 $(17.66 \pm 0.16 \mathrm{ng} / \mathrm{mL})$ 에서 유의하게 증가하였다 $(p=0.042)$. 결론적으로 대사증후군 구성요소의 증가와 대사증후군은 비타민 D의 수준과 역으로 관계가 있다.

\section{Acknowledgements: None}

Funding: None

Conflict of interest: None

\section{References}

1. Brandenburg VM, Vervloet MG, Marx N. The role of vitamin D in cardiovascular disease: From present evidence to future perspectives. Atherosclerosis. 2012, 225:253-263.

2. Carr MC. The emergence of the metabolic syndrome with menopause. J Clin Endocrinol Metab. 2003, 88:2404-2411.

3. Cozzolino M, Stucchi A, Rizzo MA. Vitamin D receptor activation and prevention of arterial ageing. Nutrition, metabolism, and cardiovascular diseases. 2012, 22:547-552.

4. Ford ES, Giles WH, Dietz WH. Prevalence of the metabolic syndrome among US adults: findings from the third National Health and Nutrition Examination Survey. JAMA. 2002, 287:356-359.

5. Grundy SM. Metabolic syndrome: a multiplex cardiovascular risk factor. J Clin Endocrinol Metab. 2007, 92:399-404.

6. Guasch A, Bulló M, Rabassa A, Bonada A, Castillo DD, Sabench
$\mathrm{F}$, et al. Plasma vitamin D and parathormone are associated with obesity and atherogenic dyslipidemia: a cross-sectional study. Cardiovasc Diabetol. 2012, 11:149.

7. Hollis BW, Horst RL. The assessment of circulating $25(\mathrm{OH}) \mathrm{D}$ and 1,25(OH)2D: where we are and where we are going. J. Steroid. Biochem. Mol Biol. 2007, 103:473-476.

8. Isomaa B, Almgren P, Forsen B, Torsen B, Laht K, Nissen M, et al. Cardiovascular morbidity and mortality associated with the metabolic syndrome. Diabetes Care. 2001, 24:683-689.

9. Khader YS, Batieha A, Jaddou H, Batieha Z, El-Khateeb M, Ajlouni K. Relationship between 25-Hydroxyvitamin D and metabolic syndrome among Jordanian adults. Nutr Res Pract. 2011, 5:132-139.

10. Kim HM, Park J, Ryu SY, Kim J. The effect of menopause on the metabolic syndrome among Korean women: the Korean National Health and Nutrition Examination Survey, 2001. Diabetes Care. 2007, 30:701-706.

11. Kim YE. The association between vitamin D deficiency and frailty syndrome. J Korean life Insur Med Assoc. 2007, 26:3-12.

12. Lagunova Z, Porojnicu AC, Vieth R. Serum 25-hydroxyvitamin $\mathrm{D}$ is a predictor of serum 1,25-dihydroxyvitamin $\mathrm{D}$ in overweight and obese patients. Pediatric diabetes. 2011, 141: 112-117.

13. Lee HJ, Kwon HS, Park YM, Chun HN, Choi YH, Ko SH, et al. Waist circumference as a risk factor for metabolic syndrome in Korean adult evaluation from 5 different criteria of metabolic syndrome. J Korean Diabetes Assoc. 2005, 29:48-56.

14. Lee KS, Yoon YS, Yoon H. The association of abdominal obesity, obesity and parathyroid hormone in Korean adults (aged $\geq 50$ years): The Korea National Health and Nutrition Survey, 2011.J Korea Acad Industr Coop Soc. 2015, 16:3882-3888.

15. Lee SH, Kim SM, H. S. Park HS. Serum 25-hydroxyvitamin D levels, obesity and the metabolic syndrome among Korean children. Nutr Metab Ccardiovas. 2013, 23:785-791.

16. Lu L, Yu Z, Pan A, Hu FB, Franco OH, Li H, et al. Plasma 25-Hydroxyvitamin D concentration and metabolic syndrome among middle-aged and elderly Chinese individuals. Diabetes Care. 2009, 32:1278-1283.

17. McNeill AM, Rosamond WD, Girman CK, Golden SH, Schmidt ML, East HE, et al. The metabolic syndrome and 11-year risk of incident cardiovascular disease in the Atherosclerosis Risk in Communities Study. Diabetes Care. 2005, 28:385-390.

18. Meigs JB. Invited commentary: insulin resistance syndrome "syndrome X" multiple metabolic syndrome a syndrome at all factor analysis reveals patterns in the fabric of correlated metabolic risk factors. Am J Epidemiol. 2000, 152:908-911.

19. Misr M, Pacaud D, Petryk A, Collett-Solberg PF, Kappy M. Vitamin D deficiency in children and its management: review of current knowledge and recommendations. Pediatrics. 2008, 122:398-417.

20. Moon HK, Kim YD, Yang DG, Kim SG, Cha KS, Kim MH, et al. Age and Gender Distribution of Patients with Acute Myocardial Infarction Admitted to University Hospitals during the Period of 1990-1999. Korean Circ J. 2003, 33:92-96.

21. Muscogiuri G, Sorice GP, Ajjan R. Can vitamin D deficiency cause diabetes and cardiovascular diseases: Present evidence and future perspectives. Nutr Metab Ccardiovas. 2012, 22: 
81-87.

22. NCEP; NHLBI; NIH. Expert panel on detection, evaluation, and treatment of high blood cholesterol in adults (adult treatment panel III). JAMA. 2001, 285:2486-2497.

23. Park HY, Lim YH, Kim JH, Bae SH, Oh SY, Hong YC. Association of serum 25-hydroxyvitamin D levels with markers metabolic syndrome in the elderly: A repeated measure analysis. J Korean Med Sci. 2012;27:653-660.

24. Park SM, Lee BK. Vitamin D deficiency is an independent risk factor for cardiovascular disease in Koreans aged years: results from the Korean National Health and Nutrition Examination Survey. Nutr Res Pract. 2012, 6:162-168.

25. Prentice A, Goldberg GR, Schoenmakers I. Vitamin D across the lifecycle: physiology and biomarkers. Am J Clin Nutr. 2008, 88:500-506.

26. Reaven GM. Role of insulin resistance in human disease.
Diabetes. 1998, 37:1598-1607.

27. Shin HA, Om AS. The correlation between dietary intake of calcium and vitamin D and osteoporosis, hypertension and diabetes mellitus. Korean Dairy Techno. 2009, 27:17-23.

28. Shin KA. Prevalence of metabolic syndrome according to menopausal status: The 5th Korea National Health \& Nutrition Examination Survey. Korean J Clin Lab Sci. 2014, 46:85-90.

29. WHO; IASO; IOTF. The Asia-Pacific perspective: Redefinding obesity and its treatment. 2000, World Health Organization, Geneva.

30. Yoon H, Kim GS, Kim SG, Moon AE. The relationship between metabolic syndrome and increase of metabolic syndrome score and serum vitamin D levels in Korean adults: 2012 Korean National Health and Nutrition Examination Survey. J Clin Biochem Nutr. 2015, 57:82-87. 